\title{
An Amino Acid-Oligosaccharide Complex Increases Mineral Bioavailability In Vitro
}

\section{Rabovsky $\mathrm{AB}^{1 *}$ and William Diehl-Jones ${ }^{2}$}

${ }^{1}$ Research and Technology Development, Melaleuca, Inc. Idaho Falls, ID, USA

${ }^{2}$ Faculty of Health Disciplines, Athabasca University, University Drive, Athabasca, AB, Canada

\begin{abstract}
Limitations in the efficacy of mineral supplements include poor solubility at intestinal $\mathrm{pH}$, low bioavailability and, particularly in the case with iron and copper, catalysis of oxidation. To address these limitations we tested a novel amino acid-oligosaccharide complex in a previously-validated in vitro digestion/absorption system. A proprietary multimineral/ multivitamin admixture in either the novel organic or inorganic mineral forms were subjected to simulated gastric and intestinal digestion, followed by apical exposure to Caco-2/HT-29MTX enterocyte co-cultures. Bioavailability was assessed by minerals and ascorbic acid analysis of fluid from the basolateral culture compartment. Intracellular oxidative flux was measured using the fluorescent probe 5-(and-6)-chloromethyl-2, 7-dichlorodihydrofluorescein diacetate acetyl ester (CM-H $\mathrm{H}_{2}$ DCFDA). Compared to the inorganic mineral form, the organic matrix yielded significant increases in mineral solubility, and yielded several-fold increases in basolateral concentrations of all minerals tested (manganese 3.3x; copper 3.1x; iron 2.1x; and zinc 4.4x) compared to the inorganic matrix. Cells exposed to the organic formulation also had significantly lower levels of intracellular oxidation after a one-hour treatment. We conclude that the amino acid oligo-fructose formulation significantly increases mineral and ascorbic acid bioavailability and decreases intracellular oxidative stress in vitro.
\end{abstract}

\section{Keywords: Minerals; Bioavailability; In vitro}

Abbreviations: AAOS: Amino Acid Oligosaccharide; AAPH: 2,2'-Azobis-2-Methyl-Propanimidamide,Dihydrochloride; $\quad$ CMH DCFDA: 5-(and-6)-Chloromethyl-2, 7-Dichlorodihydrofluorescein Diacetate Acetyl; DMT-1: Divalent Metal Transporter 1; TEER: Transepithelial Electrical Resistance; REMS: Automated Tissue Resistance Measuring System

\section{Introduction}

Approximately $40 \%$ of the American population consumes supplemental vitamins on a daily basis [1], frequently formulations of multivitamins and minerals. Of the latter, iron is particularly important: iron deficiency anemia afflicts as many as two billion people world-wide [2]. If not treated, iron deficiency causes a variety of clinical morbidities, including delayed growth, delayed cognitive mental development, and comorbidities ranging from immune suppression to psychiatric disturbances [3-5]. Given the importance of dietary iron in human health, as well as other minerals and vitamins, food fortification and or vitamin supplements have been recommended as preferred approaches for preventing and eradicating iron and mineral deficiencies. While there are currently many different brands of commercially-available multivitamin/mineral formulations, most of the minerals are provided as inorganic complexes, including sulfates, chlorides, or oxides. Whether these formulations are truly bioavailable has not always been a marketing consideration. In fact, some vitamin and mineral complexes have a relatively low rate of uptake in vivo [6].

Generally minerals are consumed as part of a multivitamin/multi mineral formulation. Aside from poor solubility of some mineral forms at intestinal $\mathrm{pH}$, they also may catalyze oxidation by generating free radicals and related oxidants, which can lead to degradation of accompanied vitamins and antioxidants and be harmful to general homeostasis. Indeed, fortification with mineral sources presents multiple challenges, not the least of which is the bioavailability $[2,7]$. From a pharmacological perspective, bioavailability is taken to mean the fraction of an oral dose that reaches systemic circulation [8]. This in turn is dependent on a variety of parameters, including solubility, enteral uptake, and first pass metabolism. Furthermore, mineral bioavailability may be reduced by mineral-specific factors such as complexation with other macro molecules, including proteins, oxidation (e.g., ferrous
$\left(\mathrm{Fe}^{2+}\right)$ to ferric $\left(\mathrm{Fe}^{3+}\right)$ iron transformation), or interactions with mucin within the unstirred layer adjacent to absorptive cells. With respect to iron in particular, conversion from the ferrous to ferric state can generate hydroxyl free radicals and other oxidants leading to a wide range of oxidative events [9] thereby contributing to redox imbalances [10].

A number of studies have assessed iron solubility after gastrointestinal digestion, which turns out to be a reasonably reliable predictor of bioavailability, but this does not incorporate the possible effects of proteins [7]. Short of doing clinical human mineral uptake studies, a more realistic approach to the measurement of bioavailability would be to combine in vitro digestion with an appropriate model of the enterocyte absorptive lining of the gastrointestinal system. Robust models of this type have been developed, relying on the well-characterized Caco-2 enterocyte cell line $[11,12]$. More recently, Caco-2/HT-29MTX co-cultures have been developed that take advantage of the mucin-secretory activity of the latter cell line, with the aim of producing an endogenous mucin layer more representative of the apical microenvironment of the gastrointestinal epithelium [12-14]. We report herein on a new mineral delivery system: an amino acid-oligosaccharide (AAOS) complex that was developed with the aim of significantly increasing mineral solubility and, ultimately, bioavailability [15]. To facilitate side-by-side comparisons of this preparation with traditional inorganic preparations, we developed two formulations with identical vitamins and excipient matrices and amount of minerals, but only differed by mineral forms: Formulation 1 AAOS, Formulation 2 - inorganic (sulfates, chlorides, and oxides).

*Corresponding author: Alexander Rabovsky, Research and Technology Development, Melaleuca, Inc. Idaho Falls, ID, USA, Tel: 208-522-0700; E-mail arabovsky@melaleuca.com

Received July 22, 2015; Accepted August 12, 2015; Published August 20, 2015

Citation: Rabovsky AB, Diehl-Jones W (2015) An Amino Acid-Oligosaccharide Complex Increases Mineral Bioavailability In Vitro. Vitam Miner 4: 132.

Copyright: (c) 2015 Rabovsky AB, et al. This is an open-access article distributed under the terms of the Creative Commons Attribution License, which permits unrestricted use, distribution, and reproduction in any medium, provided the original author and source are credited. 


\section{Goals}

Our goals in this study were to: (i) compare the intestinal uptake of minerals from two identical multivitamin/mineral formulas that vary only in the form of the minerals; and (ii) to determine whether Formulation 1 (AAOS) abrogates oxidative stress. To these ends, we utilized a previously-validated in vitro digestion/intestinal cell culture system [12]. Our hypotheses were that: (1) AAOS increases both mineral solubility and intestinal uptake; and (2) AAOS mitigates oxidative stress in enterocytes.

\section{Materials and Methods}

\section{Formulation}

The amount of vitamins and minerals in both Formulations was based on FDA-recommended $100 \%$ daily intakes (Daily Values for Nutrition Labeling, 21 CFR $\$ 101.9$ (c) and CFR \$101.36(b) (2) (ii) (B)) with the exception of calcium and magnesium. Microminerals such as copper, iron, zinc, manganese, chromium, and molybdenum were in the form of AAOS in Formulation 1 and in inorganic form in Formulation 2. Complete formulas are shown in Table 1. Vitamin A, vitamin C, vitamin D, vitamin E, vitamin $\mathrm{K}$, thiamin, riboflavin, niacin, vitamin $\mathrm{B} 6$, folate, vitamin $\mathrm{B} 12$, biotin, pantothenic acid, microcrystalline cellulose, croscaramellose sodium, silicone dioxide, magnesium stearate, and carnauba wax were purchased from Sigma Chemical Co, St. Louis, MO. Calcium carbonate, magnesium oxide, potassium iodide, copper sulfate, iron sulfate, zinc sulfate, manganese sulfate, chromium chloride, and sodium molybdate were purchased from Spectrum Chemical. AAOS minerals were prepared as previously described [15]. The USP grade amino acids were used for preparation of AAOS; glycine (CAS 56-40-6) and L-aspartic acid (CAS 56-84-8-L).

\section{In vitro digestion protocol}

In the gastric phase, the equivalent of 1 tablet of either Formulation 1 or Formulation 2 was dissolved in different concentrations in simulated gastric juice, which includes pepsin (Sigma Chemical, St. Louis, MO) ( $0.2 \mathrm{~g}$ pepsin dissolved in $5 \mathrm{~mL}$ of $0.1 \mathrm{M} \mathrm{HCl}$, adjusted to $\mathrm{pH}$ 2.0. addition of $\mathrm{HCl}$ ). Samples were incubated at $37^{\circ} \mathrm{C}$ in a shaking incubator for $30 \mathrm{~min}$. Formulation 1 samples were adjusted to $\mathrm{pH} 5.0$ by addition of $\mathrm{NaHCO}_{3}$ and incubated for a further $30 \mathrm{~min}$ in the intestinal phase, $1.25 \mathrm{~mL}$ of pancreatin (Sigma)/bile (Sigma) solution $(0.05 \mathrm{~g}$ of pancreatin and $0.3 \mathrm{~g}$ of bile extract dissolved in 25 $\mathrm{mL}$ of $0.1 \mathrm{M} \mathrm{NaHCO}_{3}$ ) and $17.2 \mathrm{mU}$ of lactase (Sigma) were added to an equal volume of Formulation 1 samples from the previous step. Samples were adjusted to $\mathrm{pH} 7.0$ by $1 \mathrm{M} \mathrm{NaHCO}_{3}$ and to a final volume of $10 \mathrm{~mL}$ by $140 \mathrm{mM} \mathrm{NaCl}$ and $5 \mathrm{mM} \mathrm{KCl}$ solution. For bioavailability testing, tablets + digestive extracts were dissolved in $230 \mathrm{~mL}$ distilled, deionized water.

\section{In vitro bioavailability testing}

Co-culture cell model: To model the human intestinal mucosa, Caco-2BBE (ATCC, Rockville, MD) cells and HT29-MTX (clone E12) cells (a kind gift of Drs. Thomas Kissel (University of Marburg) and Per Artursson (University of Lund) were co-cultured at a ratio of 9:1, respectively, in either standard 96-well tissue culture-treated multiwell tissue culture plates (for toxicity testing) or in Transwell@ plates (Corning, NY) pre-coated with $1 \%$ Matrigel $^{\circ}$ Matrix (BD Biosciences, Bedford, MA) (Figure 1) The latter is an artificial basement membrane substrate which contains matrix proteins (type IV collagen, laminin and fibronectin) that promotes cell adhesion. A total seeding density of approximately $5 \times 10^{6}$ cells $\mathrm{mL}^{-1}$ was used in all culture assays; this density precluded changes in the original ratio of Caco-2BBE: HT29MTX cells, since the latter have a shorter doubling time.

Cells were cultured in Dulbecco's Modified Eagle's Medium (DMEM) (Gibco, St. Burlington, On) with $5 \mathrm{~mL}$ of a $100 \mathrm{U} \mathrm{mL}^{-1}$ penicillin/ $100 \mu \mathrm{g} \mathrm{mL} \mathrm{mL}^{-1}$ streptomycin solution, $10 \mathrm{~mL} 2 \mathrm{mM}$ L-glutamine solution, $5 \mathrm{~mL} 1 \mathrm{mM}$ sodium pyruvate solution, $5 \mathrm{~mL} 10$ $\mu \mathrm{g} \mathrm{mL}{ }^{-1}$ human transferrin solution, and $60 \mathrm{~mL} \mathrm{10 \%} \mathrm{fetal} \mathrm{bovine} \mathrm{serum}$ per $500 \mathrm{~mL}$ DMEM. Fresh culture medium was routinely changed every two days, and experiments initiated between 14 and 21 days of subculturing. Prior to experiments, culture confluency was confirmed optically and via measurement of transepithelial electrical resistance (TEER) using an REMS autosampler (WPI, Sarasota, FL). Transwell cultures were presumed confluent when a TEER value of $300 \Omega \mathrm{cm}^{-2}$ was attained.

\section{In vitro toxicity}

To confirm that Formulation 1 is not cytotoxic, both digested and non-digested were incubated with co-cultures grown in 12-well

\begin{tabular}{|c|c|c|}
\hline Ingredient & $\begin{array}{l}\text { Amount Per } \\
\text { Serving }\end{array}$ & $\%$ Daily Value \\
\hline \multicolumn{3}{|l|}{ Common ingredients } \\
\hline Vitamin A (as beta carotene) & $5000 \mathrm{IU}$ & $100 \%$ \\
\hline Vitamin C (as ascorbic acid) & $60 \mathrm{mg}$ & $100 \%$ \\
\hline Vitamin D (as cholecalciferol) & $400 \mathrm{IU}$ & $100 \%$ \\
\hline Vitamin E (as d-alpha tocopheryl succinate) & $30 \mathrm{IU}$ & $100 \%$ \\
\hline Vitamin $\mathrm{K}$ (as phytonadione) & $80 \mu \mathrm{g}$ & $100 \%$ \\
\hline Thiamin (as thiamin $\mathrm{HCl}$ ) & $1.5 \mathrm{mg}$ & $100 \%$ \\
\hline Riboflavin & $1.7 \mathrm{mg}$ & $100 \%$ \\
\hline Niacin (as niacinamide) & $20 \mathrm{mg}$ & $100 \%$ \\
\hline Vitamin $\mathrm{B} 6$ (as pyridoxine $\mathrm{HCl}$ ) & $2 \mathrm{mg}$ & $100 \%$ \\
\hline Folate (as folic acid) & $400 \mu \mathrm{g}$ & $100 \%$ \\
\hline Vitamin B12 (as cyanocobalamin) & $6 \mu \mathrm{g}$ & $100 \%$ \\
\hline Biotin (as d-biotin) & $300 \mu \mathrm{g}$ & $100 \%$ \\
\hline Pantothenic Acid (as calcium pantothenate) & $10 \mathrm{mg}$ & $100 \%$ \\
\hline Calcium (as calcium carbonate) & $100 \mathrm{mg}$ & $10 \%$ \\
\hline Magnesium (as magnesium oxide) & $40 \mathrm{mg}$ & $10 \%$ \\
\hline lodine (as potassium iodide) & $150 \mu \mathrm{g}$ & $100 \%$ \\
\hline microcrystalline cellulose & $121 \mathrm{mg}$ & \\
\hline croscaramellose sodium & $12 \mathrm{mg}$ & \\
\hline silicon dioxide & $12 \mathrm{mg}$ & \\
\hline magnesium stearate & $4 \mathrm{mg}$ & \\
\hline carnauba wax & $0.14 \mathrm{mg}$ & \\
\hline \multicolumn{3}{|l|}{ Formulation 1- AAOS } \\
\hline Iron (as iron AAOS) & $18 \mathrm{mg}$ & $100 \%$ \\
\hline Zinc (as zinc AAOS) & $15 \mathrm{mg}$ & $100 \%$ \\
\hline Selenium (as selenium AAOS) & $70 \mu \mathrm{g}$ & $100 \%$ \\
\hline Copper (as copper AAOS) & $2 \mathrm{mg}$ & $100 \%$ \\
\hline Manganese (as manganese AAOS) & $2 \mathrm{mg}$ & $100 \%$ \\
\hline Chromium (as chromium AAOS) & $120 \mu \mathrm{g}$ & $100 \%$ \\
\hline Molybdenum (as molybdenum AAOS) & $75 \mu \mathrm{g}$ & $100 \%$ \\
\hline \multicolumn{3}{|l|}{ Formulation 2- Inorganic } \\
\hline Iron (as iron sulfate) & $18 \mathrm{mg}$ & $100 \%$ \\
\hline Zinc (as zinc sulfate) & $15 \mathrm{mg}$ & $100 \%$ \\
\hline Selenium (as L-selenomethionine) & $70 \mu \mathrm{g}$ & $100 \%$ \\
\hline Copper (as copper sulfate) & $2 \mathrm{mg}$ & $100 \%$ \\
\hline Manganese (as manganese sulfate) & $2 \mathrm{mg}$ & $100 \%$ \\
\hline Chromium (as chromium chloride) & $120 \mu \mathrm{g}$ & $100 \%$ \\
\hline Molybdenum (as sodium molybdate) & $75 \mu \mathrm{g}$ & $100 \%$ \\
\hline
\end{tabular}

Table 1: Multivitamin/Multi Mineral Formulations. 


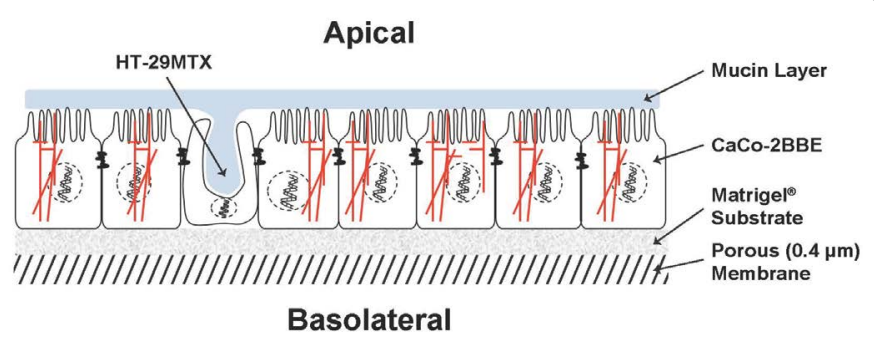

Figure 1: Co-culture model for bioavailability testing of minerals. Test solutions were added to the apical surface of confluent co-cultures.

plates. Cells were gently trypsinized, and washed in fresh culture medium containing $5 \%$ fetal bovine serum. After aspiration, cells were centrifuged for $5 \mathrm{~min}$ at $100 \mathrm{~g}$, the medium aspirated, and the cells resuspended in phosphate-buffered saline (PBS). Cells were then mixed with 1 part of $0.4 \%$ trypan blue to an equal part cell suspension and the mixture incubated $3 \mathrm{~min}$ at $\sim$ room temperature. Approximately $50 \mu \mathrm{L}$ each of trypan blue/cell mixture was added to a hemocytometer (American Optical, Company, Buffalo, NY), which was placed on a Zeiss IM35 inverted microscope with phase contrast optics. The unstained (viable) and stained (nonviable) cells were counted to obtain percentage of viable cells after treatment, the percentage of viable cells, which was calculated as follows: viable cells $(\%)=$ total number of viable cells per $\mathrm{mL}$ of aliquot/ total number of cells per $\mathrm{mL}$ of aliquot x100.

\section{In vitro bioavailability}

In vitro solubility was assessed as metals concentration in Formulation 1 and 2 after digestion. Samples were filtrated through $0.45 \mu \mathrm{m}$ filter, acidified with $0.2 \mathrm{M}$ nitric acid and stored in glass vials until assay. Uptake and transport of metals were assessed with the Caco-2BBE/HT-29 co-cultures grown in Transwell plates. To initiate the experiments, cells were washed once in fresh MEM before adding $0.5 \mathrm{~mL}$ test solution containing either digested Formulation 1 or 2 to the apical culture surface. Cells were incubated with digested samples for 0 , 1,2 , or $3 \mathrm{~h}$ at $37^{\circ} \mathrm{C}$ in a humidified atmosphere of $95 \%$ air and $5 \% \mathrm{CO}_{2}$. Aliquots $(1000 \mu \mathrm{L})$ of basal culture medium were removed and either immediately frozen at $-86^{\circ} \mathrm{C}$, after which they were sent for metals analysis; alternately, samples immediately acidified with $0.2 \mathrm{M}$ nitric acid and stored in glass vials until assay. Samples were handled and transported in glass containers, because adsorption on plastic material was very significant at the extremely low metal concentration. Metals were analyzed after nitric acid digestion according to the instrument manual on ICP-MS Elan-6100 (Perkin Elmer, Waltham, MA).

\section{Intracellular oxidative flux}

The impact of Formulation 1 versus Formulation 2 on the generation of reactive oxygen species in vitro was measured in accordance with widely used techniques. Briefly, the relative flux of oxidants was measured by incubating cell cultures with the fluorescent probe 5-(and6)-chloromethyl-2, 7-dichlorodihydrofluorescein diacetate acetyl ester (CM- $\mathrm{H}_{2}$ DCFDA) (Invitrogen, Eugene, OR). CM- $\mathrm{H}_{2}$ DCFDA is a cellpermeant fluorochrome that is hydrolyzed by intracellular esterase to form $\mathrm{CM}-\mathrm{H}_{2} \mathrm{DCF}$, which is retained intracellularly and is oxidized by oxidants such as, activated $\mathrm{Fe}^{2+}-\mathrm{O}_{2}$ derived species, heme peroxidases, peroxyl, and hydroxyl radicals [16]. Fluorescence intensity increases with the level of oxidation, thereby reporting on the relative flux of intracellular oxidants [17]. Co-cultures were grown in 96 black-well (clear bottom) plates until confluence. Except for background controls ('blank'), cells in each microplate well were loaded with $10 \mu \mathrm{M} \mathrm{CM}$ $\mathrm{H}_{2} \mathrm{DCFDA}$ for $30 \mathrm{~min}$. Probe was then aspirated and co-cultures were incubated with either Formulation 1 or Formulation 2. After aspiration of treatment solutions and a 5-min wash with PBS, fluorescence intensities were measured with a Fluoroskan Ascent ${ }^{\oplus}$ fluorometer (Thermo Scientific, Newington, NH) (485 nm excitation, $527 \mathrm{~nm}$ emission) after $0,15,30,45$, and 60 min incubation at $37^{\circ} \mathrm{C}$. Positive controls consisted of cells oxidatively challenged by addition of $1 \mathrm{mM}$ fresh AAPH. After aspiration of treatment solutions cells were washed with PBS.

\section{Metals Analysis}

Basolateral samples were immediately acidified with $1 \mathrm{mM}$ nitric acid and frozen. Metals were analyzed after nitric acid digestion by ICP-MS Elan-6100 (Perkin Elmer, Waltham).

\section{Phosphotungstate analysis of ascorbate}

Ascorbic acid analysis of basolateral fluid was conducted as described by Kyaw et al. [18]. Briefly, acid phosphotungstate reagent was prepared by combining two reagents: reagent A consisted of $20 \mathrm{~g}$ of sodium tungstate $\left(\mathrm{Na}_{2} \mathrm{WO}_{4} \cdot 2 \mathrm{H}_{2} \mathrm{O}\right)$ and $10 \mathrm{~g}$ of disodium hydrogen phosphate $\left(\mathrm{Na}_{2} \mathrm{HPO}_{4} \cdot 2 \mathrm{H}_{2} \mathrm{O}\right)$ suspend in $30 \mathrm{~mL}$ of warm water. Reagent $\mathrm{B}$ was prepared by adding $5 \mathrm{~mL}$ of sulfuric acid $\left(\mathrm{H}_{2} \mathrm{SO}_{4}\right)$ to $15 \mathrm{~mL}$ of double-distilled, de-ionized water. A final working solution of acid phosphotungstate was prepared by slowly combining reagent $B$ into warm reagent $\mathrm{A}$ and cooled to room temperature. One $\mathrm{mL}$ of basolateral cell culture fluid was mixed with $1 \mathrm{~mL}$ of $0.2 \mathrm{M}$ hydrochloric acid, vortexed then centrifuged for $1 \mathrm{~min}$ at $16000 \mathrm{~g}$ in a micro-centrifuge tube. This solution was diluted to appropriate concentration and mixed with an equal amount of acid phosphotungstate. Samples were incubated for $30 \mathrm{~min}$ at room temperature, and optical density measured at $700 \mathrm{~nm}$ using a Beckman/Coulter DU520 spectrophotometer. Blanks consisted of $1 \%$ acetic acid. A standard calibration curve was obtained with serial dilutions of ascorbic acid (range $0.0-0.2 \mathrm{mg} \mathrm{mL}^{-1}$ ).

\section{Statistical Analysis}

Results of oxidative stress assays are presented as mean \pm standard error of the mean (SEM). To avoid Type 1 errors, a one-way analysis of variance was used to determine statistical significance $(\mathrm{p}<0.05)$.

\section{Results}

\section{Viability testing}

Cell viability data is presented in Figure 2. The positive control consisted of formalin-killed cells, while the negative control consisted of cells incubated in the basal culture medium. There were no significant differences in cell viability between Formulation 1 and Formulation 2 treated cells; nor were there significant differences between the treatedcells and the negative control $(p<0.05)$.

\section{Intracellular oxidation assay}

Intracellular oxidation of the probe $\mathrm{H}_{2}$ DCF-DA was followed over one hour of exposure to either Formulation 1 or Formulation 2 at $37^{\circ} \mathrm{C}$. As indicated in Figure 3, there was a low level of dye oxidation in test wells, which did not include any cells (Dye); in the absence of a cellular milieu, the non-de-esterified indicator dye ( $\left.\mathrm{H}_{2} \mathrm{DCF}-\mathrm{DA}\right)$ does not significantly oxidize in the presence of the free radical generator AAPH. Cell cultures treated with AAPH or AAPH + Formulation 2 yielded the highest levels of intracellular fluorescence. In contrast, intracellular oxidation was significantly lower in cell cultures treated with AAPH or AAPH + Formulation 1 after 30,45 and 60 min incubation $(p<0.05)$. The trend in greater fluorescence emission intensity in presence or absence of AAPH is not statistically significant. Cell cultures treated 


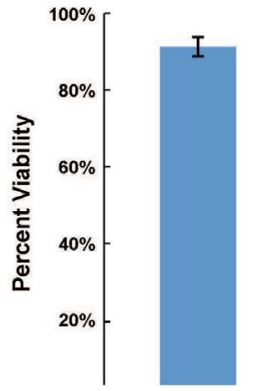

Figure 2: Effects of Formulation 1 and Formulation 2 on enterocyte viability Three replicates per treatment, with at least 100 cells counted in each group. Data are presented as mean $+/$ - standard error. Cell cultures were treated with either Formulation 1 or Formulation 2 for 1 hour.

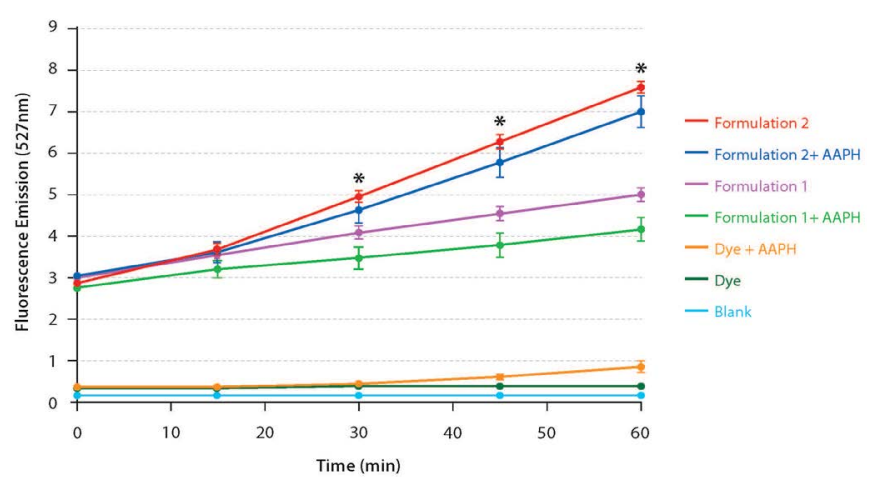

Figure 3: Effects of Formulation 1 and Formulation 2 on intracellular enterocyte oxidation. Fluorescence emission of $\mathrm{H}_{2} \mathrm{DCF}$ was measured at $527 \mathrm{~nm}$ every 15 minutes for one hour. Data are presented as the mean \pm standard error of 7 replicates (wells). Formulation 2 significantly inhibited $\mathrm{H}_{2} \mathrm{DCF}$ fluorescence in the presence of the oxidative stress inducer (AAPH). Blank = cells without ROS indicator $\left(\mathrm{CM}-\mathrm{H}_{2} \mathrm{DCF}\right)$; dye = cells incubated with $\mathrm{ROS}$ indicator (no treatment); dye $+\mathrm{AAPH}=$ cells incubated with ROS indicator and AAPH).

with Formulation 1 alone had significantly lower fluorescence signals than cells treated with Formulation 2 at 30,45 and 60 min incubation $(p<0.05)$.

\section{Solubility and bioavailability analyses}

The relative solubilities of Formulation 1 vs. Formulation 2 are depicted in Table 2. Compared to the inorganic forms, Formulation 1 showed significant increases in mineral solubility. The absolute concentrations of minerals in the basolateral culture compartments are presented in Table 3. Again, there were significant, several-fold increases in the concentrations of all minerals added in the Formulation 1 supplement compared to the inorganic matrices.

\section{Vitamin C analysis}

Data from ascorbic acid (vitamin C) determinations are presented in Table 4. Due to the very low levels, most likely due to the degradation of Ascorbate in vitro, fluid samples collected from basolateral chambers were pooled. Formulation 1 yielded higher levels of Ascorbate after incubation at both $1 \mathrm{~h}$ and $3 \mathrm{~h}$.

\section{Discussion /Summary}

AAOS form significantly increases mineral bioavailability in the Caco-2/HT-29MTX in vitro co-culture model. Furthermore, this form did not increase intracellular oxidative stress, which is consistent with our previous findings that AAOS blunts oxidative stress in vivo [15]. In this study, we used the oxidative stress probe CM- $\mathrm{H}_{2}$ DCFDA as an indicator of intracellular stress. While this thiol dye has been used in numerous studies to measure oxidative stress, we do acknowledge that the complexity of interactions between this dye and other thiols and thiol-derived radicals. Furthermore, $\mathrm{pH}$ variation and oxygen tension can confound interpretation of results of such assays [19]. Nevertheless, given the time course of our measurements, the results of both positive (AAPH-induced) and negative (no AAPH) controls, and the magnitude of differences between Formulation 1 and Formulation 2, we suggest that the effects of AAOF (Formulation 1) in blunting intracellular oxidative stress are robust.

Our intestinal cell culture system has been previously validated as an efficacious model of the in vivo state, and it is congruent with the finding that Formulation 1 increases mineral solubility. Similarly, our model provides support for the likelihood that the AAOF formulation enhances bioavailability. Further, increases in bioavailability would likely enhance systemic mineral uptake with the health benefits accrued as a result of meeting metabolic demands for these minerals. The increased mineral bioavailability conferred by Formulation 1 was at a lower level than would be predicted purely by the increased solubility in minerals in the Formulation 1 tablets. This is likely due to the fact that, while factors such as mucin enhance mineral transport, other morphological and molecular features of enterocytes regulate transmembrane flux, as depicted in Figure 4.

A key component of the current study is the side-by-side comparison of the two mineral formulations. The solubility and bioavailability of an individual mineral can be markedly different from its behavior as part of multivitamin/multimineral admixture [20]. Furthermore, it is difficult to compare different mineral forms using commercially available products; while mineral content may be the same, excipients (tablet fillers, tablets coating, flavoring and coloring additions) may have a dramatic effect on the properties exhibited by the minerals [21]. Formulations 1 (AAOS) and 2 (inorganic) differed only with respect to the mineral matrices; thus, in vitro solubility, bioavailability and biological effects most directly reflect this difference and no other confounding factors.

We propose that, by increasing the solubility of minerals, Formulation 1 also increases the amount of mineral-substrate available to transporters such as the apical DMT-1 and basolateral Ferroportin

\begin{tabular}{|c|c|c|c|c|}
\hline & Manganese & Copper & Iron & Zinc \\
\hline \multicolumn{5}{|c|}{ Metal Concentration $\left(\mu \mathrm{g} \mathrm{mL}^{-1}\right)$} \\
\hline Formulation 1 & 5.2 & 6.7 & 45.3 & 30.4 \\
\hline Formulation 2 & 0.16 & 0.16 & 1.36 & 0.69 \\
\hline
\end{tabular}

Table 2: Mineral solubility of Formulation 1 and Formulation 2 in apical compartments (Solubility).

\begin{tabular}{|c|c|c|c|c|}
\hline & Manganese & Copper & Iron & Zinc \\
\hline \multicolumn{5}{|c|}{ Metal Concentration $\left(\mu \mathrm{g} \mathrm{mL}^{-1}\right)$} \\
\hline Formulation 1 & $0.24 \pm 0.02$ & $0.28 \pm 0.03$ & $1.16 \pm 0.14$ & $1.04 \pm 0.10$ \\
\hline Formulation 2 & $0.07 \pm 0.02$ & $0.09 \pm 0.01$ & $0.56 \pm 0.08$ & $0.23 \pm 0.08$ \\
\hline
\end{tabular}

Table 3: Mineral concentration in the basolateral compartments (Bioavailability) $(n=6)$

\begin{tabular}{|l|l|l|}
\hline & $\mathbf{1}$ hour $\left(\mu \mathrm{gL}^{-1}\right)$ & $\mathbf{3}$ hours $\left(\mu \mathrm{gL}^{-1}\right)$ \\
\hline Formulation 1 & 5.79 & 7.45 \\
\hline Formulation 2 & 4.96 & 5.65 \\
\hline
\end{tabular}

Table 4: Vitamin C transport in Caco-2BBE/HT-29MTX transwell co-cultures exposed to Formulation 1 and Formulation 2. 


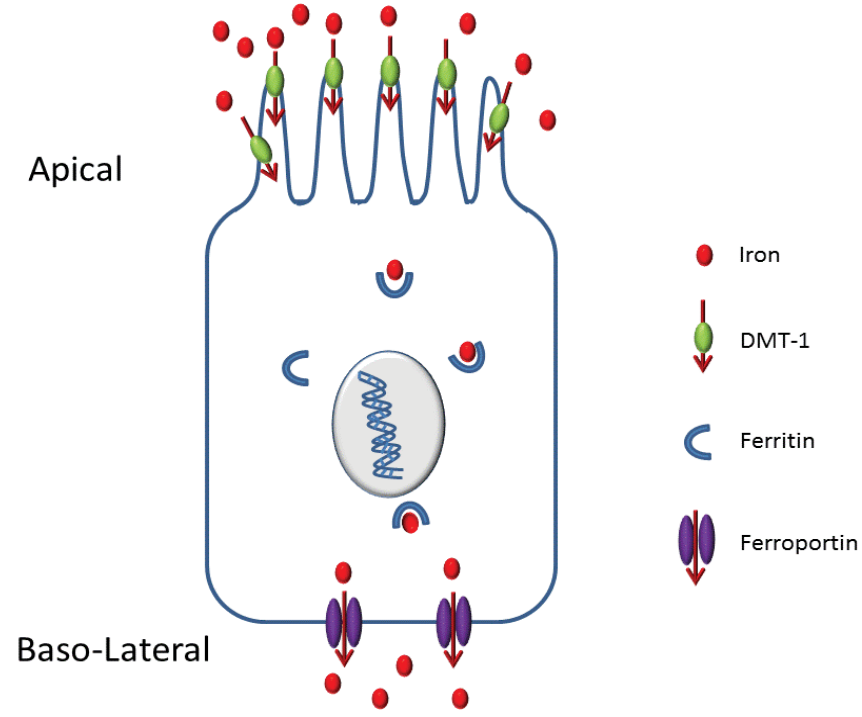

Figure 4: Diagrammatic representation of transmembrane and intracellular iron transport mechanisms in enterocyte. DMT-1 = Divalent Metal Transporter-1. Bioavailability of iron depends on the solubility of iron, as well as the presence of appropriate transporters (DMT-1 and Ferroportin) as well as intracellular ironbinding proteins (ferritin).

[22]. What is ultimately of interest is whether the increased solubility afforded by Formulation 1 (AAOS) enhances the bioavailability of physiologically-relevant minerals; based on our in vitro data, which simulates digestion and interaction with enterocytes coated with a mucin layer, we show herein that Formulation 1 does facilitate trans mural uptake of dietary metals.

While our evidence is encouraging, an important caveat is that in vitro models such as employed here are crucial adjuncts to clinical human testing, which ultimately remains the best method for determining the efficacy of mineral supplementation in vivo. Furthermore, a variety of factors can affect mineral uptake: age, gender, physiologic state, drug use [8]. Given these possible confounding variables, as well as the ethics and expense of human clinical trials, in vitro studies have an important role in helping us to understand factors that may impact the efficacy of vitamin and mineral supplementation in humans. Certainly, solubility is one such factor. By demonstrating that AAOS enhances not only solubility but also transepithelial uptake in a physiologicallyrepresentative model of the human intestinal mucosa, we suggest that our new matrix may overcome an important limitation in inorganic delivery systems.

\section{Conclusion}

AAOS significantly increases mineral and Ascorbate bioavailability in an in vitro digestion/enterocyte co-culture system when compared to an inorganic form. AAOS similarly decreases intracellular oxidative stress in vitro. Based on these findings and on our animal model, AAOS is a promising vehicle for mineral and multivitamin supplementation.

\section{References}

1. Navarro M, Wood RJ (2003) Plasma changes in micronutrients following a multivitamin and mineral supplement in healthy adults. J Am Coll Nutr 22: 124-132.

2. Mehansho $\mathrm{H}$ (2006) Iron fortification technology development: new approaches. J Nutr 136: 1059-1063.

3. Riggins T, Miller NC, Bauer PJ, Georgieff MK, Nelson CA (2009) Consequences of low neonatal iron status due to maternal diabetes mellitus on explicit memory performance in childhood. Dev Neuropsychol 34: 762-779.
4. Simpson JL, Bailey LB, Pietrzik K, Shane B, Holzgreve W (2011) Micronutrients and women of reproductive potential: required dietary intake and consequences of dietary deficiency or excess, Part II--vitamin D, vitamin A, iron, zinc, iodine and essential fatty acids. J Matern Fetal Neonatal Med 24: 1-24.

5. Stoltzfus RJ (2003) Iron deficiency: global prevalence and consequences. Food Nutr Bull 24: 99-103.

6. Yetley EA (2007) Multivitamin and multimineral dietary supplements: definitions, characterization, bioavailability and drug interactions. Am J Clin Nutr 85: 269S-276S

7. Miller DD, Berner LA (1989) Is solubility in vitro a reliable predictor of iron bioavailability?. Biol Trace Elem Res 19: 11-24.

8. Wienk KJ, Marx JJ, Beynen AC (1999) The concept of iron bioavailability and its assessment. Eur J Nutr 38: 51-75.

9. Qian SY, Buettner GR (1999) Iron and dioxygen chemistry is an important route to initiation of biological free radical oxidations: an electron paramagnetic resonance spin trapping study. Free Radic Biol Med 26: 1447-1456.

10. Sharp PA (2010) Intestinal iron absorption: regulation by dietary \& systemic factors. Int J Vitam Nutr Res 80: 231-242.

11. Etcheverry P, Wallingford JC, Miller DD, Glahn RP (2005) The effect of calcium salts, ascorbic acid and peptic $\mathrm{pH}$ on calcium, zinc and iron bio availabilities from fortified human milk using an in vitro digestion/Caco-2 cell model. Int $J$ Vitam Nutr Res 75: 171-178.

12. Yao L, Friel JK, Suh M, ehl-Jones WL (2010) Antioxidant properties of breas milk in a novel in vitro digestion/enterocyte model. J Pediatr Gastroenterol Nutr 50: $670-676$

13. Laparra JM, Glahn RP, Miller DD (2009) Different responses of Fe transporters in Caco-2/HT29-MTX cocultures than in independent Caco-2 cell cultures. Cell Biol Int 33: 971-977.

14. Mahler GJ, Shuler ML, Glahn RP (2009) Characterization of Caco-2 and HT29MTX cocultures in an in vitro digestion/cell culture model used to predict iron bioavailability. J Nutr Biochem 20: 494-502.

15. Rabovsky AB, Komarov AM, Ivie JS, Buettner GR (2010) Minimization of free radical damage by metal catalysis of multivitamin/multimineral supplements. Nutr J 9: 61

16. Hempel SL, Buettner GR, O’Malley YQ, Wessels DA, Flaherty DM (1999) Dihydrofluorescein diacetate is superior for detecting intracellular oxidants: comparison with 2',7'-dichlorodihydrofluorescein diacetate, 5(and 6)-carboxy2',7'-dichlorodihydrofluorescein diacetate, and dihydrorhodamine 123. Free Radic Biol Med 27: 146-159.

17. Mehanna C, Baudouin C, Brignole-Baudouin F (2011) Spectrofluorometry assays for oxidative stress and apoptosis, with cell viability on the same microplates: a multiparametric analysis and quality control. Toxicol in Vitro 25 : 1089-1096.

18. Kyaw A, Aung T, Htut T, Myint $\mathrm{H}$, Tin KM (1983) Lysosomal enzyme activities in normal and in patients with chronic liver diseases. Clin Chim Acta 131: 317-323.

19. Wrona M, Patel KB, Wardman P (2008) The roles of thiol-derived radicals in the use of 2',7'-dichlorodihydrofluorescein as a probe for oxidative stress. Free Radic Biol Med 44: 56-62.

20. Heaney RP, Dowell MS, Bierman J, Hale CA, Bendich A (2001) Absorbability and cost effectiveness in calcium supplementation. J Am Coll Nutr 20: 239-246.

21. Yuen $\mathrm{KH}$ (2010) The transit of dosage forms through the small intestine. Int $\mathrm{J}$ Pharm 395: 9-16.

22. Thompson BA, Sharp PA, Elliott R, Fairweather-Tait SJ (2010) Inhibitory effect of calcium on non-heme iron absorption may be related to translocation of DMT1 at the apical membrane of enterocytes. J Agric Food Chem 58: 8414-8417. 